JURNAL BASICEDU

Research \& Learning in Elementary Education

https://jbasic.org/index.php/basicedu

\title{
PENGARUH PERMAINAN GOBAK SODOR MODIFIKASI TERHADAP HASIL BELAJAR SISWA DI SEKOLAH DASAR
}

\author{
Sigit Pambudi ${ }^{1}$, Ibnu Fatkhu R $^{2}$ Diana Endah Handayani ${ }^{3}$ \\ Universitas PGRI Semarang, Jawa Tengah, Indonesia ${ }^{123}$ \\ E-mail: sigitpambudi543@gmail.com ${ }^{1}$,ibnufatkhuroyana@upgris.ac.id ${ }^{2}$,handayani.hitam@ @mail.com³
}

\begin{abstract}
Abstrak
Penelitian ini dilatar belakangi pembelajaran yang masih mengunakan teacher center/tradisional, guru masih keterbatasan media dalam pembelajaran. Hal ini mengakibatkan pada hasil belajar siswa yang tergolong masih rendah. Dengan demikian, masih terdapat beberapa peserta didik yang belum mencapai Kriteria Ketuntasan Minimal (KKM) dan karakter siswa SD yang masih suka bermain dan belajar .Permasalahan yang dikaji dalam penelitian ini adalah "apakah media? gobak sodor modifikasi berpengaruh terhadap hasil belajar Siswa Kelas IV Tema 2 Selalu Berhemat Energi SDN 01 Boyoteluk Kabupaten Pekalongan". Tujuan dalam penelitian ini adalah untuk mengetahui pengaruh media gobak sodor modifikasi terhada hasil belajar siswa kelas IV Tema 2 Selalu Berhemat Energi SDN 01 Boyoteluk Kabupaten Pekalongan. Jenis penelitian ini adalah penelitian kuantitatif dengan menggunakan metode eksperimen. Desain penelitian yang digunakan adalah True Eksperimental Design dengan Pretest-Posttest one-Group Design. Sodor modifikasi dapat mencapai ketuntasan belajar klasikal sebesar $87 \%$ dengan rata-rata nilai pretest adalah 62,8 dan rata-rata nilai posttest meningkat menjadi 76,9 . Hasil analisis uji-t diperoleh $t_{\text {hitung }}>t_{\text {tabel }}$ yaitu $67,65>1,7171$. Berdasarkan hasil analisis dapat disimpulkan bahwa $\mathrm{H}_{0}$ ditolak dan $\mathrm{H}_{\mathrm{a}}$ diterima, artinya media gobak sodor modifikasi berpengaruh terhadap hasil belajar siswa kelas IV tema 2 selalu berhemat energi SDN 01 Boyoteluk Kabupaten Pekalongan.
\end{abstract}

\section{Kata kuci : Media Gobak Sodor Modifikasi, Hasil Belajar, Tema 2 Selalu Berhemat Energi}

\begin{abstract}
This research is motivated by learning that still uses the teacher center / traditional, the teacher is still limited by media in learning. This results in student learning outcomes that are still relatively low. Thus, there are still some students who have not yet reached the Minimum Mastery Criteria (KKM) and the character of elementary school students who still like to play and learn. The problem examined in this study is "what is the media? modification sodor gobak influences student learning outcomes Class IV Theme 2 Always Save Energy SDN 01 Boyoteluk Pekalongan Regency ". The purpose of this study was to determine the effect of the Sodor Modification media on student learning outcomes in class IV Theme 2 Always Save Energy SDN 01 Boyoteluk, Pekalongan Regency. This type of research is quantitative research using experimental methods. The research design used was True Experimental Design with Pretest-Posttest one-Group Design. Sodor modification can achieve classical learning completeness of $87 \%$ with an average pretest value of 62.8 and the average posttest score increased to 76.9. The results of t-test analysis obtained tcount $>$ ttable is 67.65> 1.7171. Based on the results of the analysis it can be concluded that $\mathrm{HO}$ is rejected and Ha is accepted, meaning that the modification of the Sodobak media influences the learning outcomes of Grade IV students in Theme 2 always saving energy on SDN 01 Boyoteluk in Pekalongan Regency.
\end{abstract}

Key words: Modified Gobak Sodor Media, Learning Outcomes, Theme 2 Always Save Energy

@ Jurnal Basicedu Prodi PGSD FIP UPTT 2019

$\triangle$ Corresponding author :

Address :

Email : : sigitpambudi543@gmail.com

ISSN 2580-3735 (Media Cetak)

Phone : ISSN 2580-1147 (Media Online) 
874 Pengaruh Permainan Gobak Sodor Modifikasi terhadap Hasil Belajar Siswa di Sekolah Dasar- Sigit pambudi, Ibnu Fatkhu R, Diana Endah Handayani

\section{PENDAHULUAN}

Pendidikan Nasional berfungsi mengembangkan kemampuan dan membentuk karakter serta peradaban bangsa yang bermartabat dalam rangka mencerdaskan kehidupan bangsa. Maka sangat diharapkan adanya perubahan sikap ataupun karakter secara menyeluruh pada peserta didik agar tujuan pendidikan nasional untuk mengembangkan potensi siswa menjadi manusia yang beriman dan bertakwa kepada Tuhan Yang Maha Esa, berakhlak mulia, sehat, berilmu, cakap, kreatif, mandiri, dan menjadi warga negara yang demokratis serta bertanggung jawab (UU No 20 Tahun 2003) dalam (Morelent dan sofiyani, 2015: 142)

Rossi dan breiddle dalam Sanjaya (2012: 58) mengemukakan bahwa media pembelajaran adalah seluruh alat dan bahan yang dapat dipakai untuk tujuan pendidikan seperti radio, televisi, buku, koran, majalah dan sebagainya. Gerlach dan Ely dalam Sanjaya (2012: 59-60) memandang media pembelajaran bukan hanya berupa alat dan bahan saja, akan tetapi hal-hal yang memungkinkan siswa dapat memperoleh pengetahuan.

Media permainan gobak sodor salah satu media yang mendasar pada karakter siswa sekolah dasar lebih suka bermain serta belajar. Dalam permainan gobak sodor mengajarkan sikap kerjasama dan kedisiplinan. Jean piaget dalam Danim (2014 : 64) anak diusia 7-11 tahun merupakan tahap operasional konkret, anak di usia ini dibatasi untuk berfikir konkret -nyata, pasti, tepat, dan uni-direksional- istilah yang lebih menunjukan pengalaman nyata dan konkret ketimbah abstraksi. Danim (2014 :62) Pada saat ini, anak-anak suka lari, melompat, meloncat, melempar, menangkap, memanjat, dan keseimbangan. Seperti halnya anak usia sekolah, pertumbuhan fisik anak-anak pada umumnya menjadi cepat, kuat dan terkoordinasi. oleh karena itu, anak menjadi lebih mahir dalam kegiatan motorik kasar. Jadi anak kelas IV mudah diarahan untuk melakukan permainan tersebut.

Guru dituntut mampu memilih strategi pembelajaran dengan tepat agar peserta didik mudah dalam memahami materi pelajaran dan pembelajaran tercapai, guru diharuskan menguasai model, metode dan media, dalam menyampaikan pembelajaran dengan mengunakan media membuat siswa tertarik dalam mengikuti pembelajaran serta membuat siswa tidak bosan.

Berdasarkan hasil wawancara dengan $\mathrm{Bu}$ Dyna Wijayanti, S.pd.SD guru kelas IV SDN 01 Boyoteluk Kabupaen Pekalongan, terdapat suatu permasalahan dalam pembelajaran yang digunakan masih teacher center / tradisional, karakter siswa SD yang masih suka bermain dan belajar, keterbatasan media dalam pembelajaran terlihat dari nilai ulangan harian yang belum optimal.Dari 23 peserta didik pada kelas IV yang belum mencapai KKM pada nilai PJOK 48\%, IPA 61\% dan Bahasa Indonesia 13\% yang sudah tercapai di kreteria ketuntasan (KKM) Namun belum optimal karena belum mencapai $75 \%$ terlihat di nilai ratarata kelas. jumlah siswa 23 dengan nilai rata-rata dalam pembelajaran tematik yang terdapat beberapa mata pelajaran antara lain PJOK 73,1\%, IPA $71,3 \%$ dan Bahasa Indonesia nilai rata-rata kelas cukup tinggi samapai 79\% dengan semua nilai KKM 75.

Berdasarkan hasil wawancara yang dilakukan peneliti mendapat permasalahan belajar dalam pembelajaran tematik kelas IV SD Negeri 01 Boyoteluk Kabupaten Pekalongan dengan permasalahan hasil belajar peseta didik belum mencapai nilai KKM yang di tentukan, media yang digunakan guru monoton dan jarang mengunakan media pembelajaran. Dengan demikian peneliti akan melakukan penelitian esperimen, untuk 
875 Pengaruh Permainan Gobak Sodor Modifikasi terhadap Hasil Belajar Siswa di Sekolah Dasar- Sigit pambudi, Ibnu Fatkhu R, Diana Endah Handayani

mengetahu dampak setelah mendapat perlakuan dari peneliti ke subyek yang di teliti.

Dengan keterbatasan media dalam pembelajaran mengakibatkan pemahaman peserta didik terhadap pembelajaran kurang maksimal serta hasil belajar peserta didik masih tergolong rendah. dengan itu perlu adanya pembelajaran yang menarik untuk meningkatkan semangat belajar peserta didik serta meningkatkan hasil belajar, salah satunya dengan cara guru akan mengunakan media dalam peroses belajar mengajar khususnya pada pembelajaran Tema 2 Selalu Berhemat Energi yaitu dengan media bantu Gobak Sodor Modifikasi. Di harapkan materi yang di sampaikan guru dengan media Gobak Sodor Modifikasi dapat meningkatkan hasil belajar peserta didik.

Penelitian akan bereksperimen dengan mengunakan pembelajaran dengan media Gobak Sodor Modifikasi, pada awal penelitian peneliti akan memberikan soal pretest terhadap pesrta didik kelas IV, kemudian peneliti memberikan perlakuan pada peserta didik dengan melakukan pembelajaran menggunakan media Gobak Sodor Modifikasi.Selanjutnya, peneliti memberikan soal posttest.

\section{METODE}

Penelitian ini menggunakan desain PreExperimental dengan metode eksperimen berupa One- Group Pretest- Posttest Design. Pada desain ini terdapat pretest, sebelum di beri perlakuan, dengan demikian hasil perlakuan dapat diketahui lebih akurat, karena dapar membandingkan dengan keadaan sebelum diberi perlakuan. Desain ini dapat digambarkan sebagai berikut.

\section{Tabel 1 Desain Penelitian}

\begin{tabular}{|l|l|l|}
\hline Pretest & Perlakuan & Posstest \\
\hline $\mathrm{O}_{1}$ & $\mathrm{X}$ & $\mathrm{O}_{2}$ \\
\hline
\end{tabular}

$\mathrm{O}_{1}=$ Nilai Pretest (Sebelum diberi diklat)

$\mathrm{O}_{2}=$ Nilai Posttest (Setelah diberi diklat)
$\mathrm{X}=$ Perlakun yang mengunakan Media Gobak Sodor Modifikasi

Sugiyono, (2016:111)

Populasi adalah wilayah generasi yang terdiri atas: obyek/subyek yang mempunyai kualitas dan karakteristik tertentu yang ditetepkan oleh peneliti untuk dipelajari dan kemudian ditarik kesimpulanya.(Sugiyono, 2016: 117) Populasi yang akan digunkan penelitian ini adalah peserta didik kelas IV SD Nengri 01 Boyoteluk tahun ajaran 2018/2019.

Sampel adalah bagian dari jumlah dan krakteristik yang dimiliki oleh populasi tersebut. Bila populasi besar, dan peneliti tidak mungkin mempelajari semua yang ada pada populasi, misalnya karena keterbatasan dana, tenaga dan waktu, maka peneliti dapat menggunakan sampel dari populasi itu. Apa yang dipelajari dari sampel itu, kesimpulanya akan dapat diberlakukan untuk populasi. (Sugiyono, 2016: 118)Sampel dalam penelitian ini adalah peserta didik SD Negri 01 Boyoteluk kelas IV berjumlah 23 peserta didik.

Sugiyono (2016: 118) mengemukakan tekniksampling merupakan teknik pengambilan sampel. Untuk menentukan sampel yang akan digunakan dalam penelitian terdapat berbagai teknik sampling yang digunakan. dalam penelitian ini adalah teknik kelompok atau rumpun jenis Nonprobability Sampling dengan Sampling jenuh.

Sampling jenuh adalah teknik penentuan sampel bila semua anggota populasi digunakan sebagai sampel. Hal ini sering dilakukan bila jumlah populasi relatif kecil, kurang dari 30 orang atau penelitian yang ingin membuat generalisasi dengan kesalahan yang sangat kecil. (Sugiyono, 2016: 124), alasan peneliti menggunakan sampling jenuh karena jumlah peserta didik hanya 23 di kelas IV SDN 01 Boyoteluk 01kabupaten pekalongan. 
Teknik pengumpulan data Agar penelitian ini dapat dipercaya maka data yang di peroleh peneliti harus benar pengumpulan data dalam penelitian eksperimen yang dilakukan peneliti dengan metode sebagi berikut: Observasi ,Wawancara, Kuesioner (angket), Dokumentasi dan Tes.

Menurut Sugiyono (2016: 148) "Instrumen penelitian adalah suatu alat mengukur fenomena alam maupun social yang diamati, secara spesifik semua fenomena ini disebut variabel penelitian". Instrumen penelitian ini merupakan suatu yang digunakan dalam pengumpulan data agar aktifitas penelitianya menjadi mudah dan hasilnya lebih baik, dalam arti cermat, lengkap dan sistematis, sehingga penelitianya tidak sulit diolah, saat pengumpulan data supaya dalam melakukan penelitian dapat terarah sesuai dengan rencana peneliti. Instrumen yang digunakan dalam penelitian ini antara lain sebagai berikut: Rencana Pelaksanaan Pembelajaran (RPP), Silabus, Lembar Observasi dan kisi-kisi.

\section{HASIL DAN PEMBAHASAN}

Dalam penelitian ini penilaian ranah Ketrampilan meliputi keperdulian terhadap sumber daya alam terdapat dalam pertemuan 1, Pelaksanaan hak dan kewajiban dan menyanyi terdapat dalam pertemua 2, pelaksanaan gerak dasar lokomotor dan non lokomotor terdapat dalam pertemunan 3, tulisan hasil analisis gambar aktifitas perubahan bentuk energi terdapat dalam pertemuan 1 dan 3 , dan menulis teks petunjuk cara penggunaan listrik yang aman terdapat dalam pertemuan 1 dan 3, Berikut tabel penilaian ranah keterampilan:
Tabel 2 Penilaian Ranah Ketrampilan

\begin{tabular}{|c|c|c|c|c|}
\hline No. & Pertemuan Ke- & $\begin{array}{l}\text { Mata } \\
\text { pelajaran }\end{array}$ & Penilaian Ketrampilan & Rata-rata \\
\hline \multirow[t]{3}{*}{1} & \multirow[t]{3}{*}{ Pertemuan 1} & IPS & $\begin{array}{l}\text { Keperdulian terhadap } \\
\text { Sumber daya alam }\end{array}$ & 70,57 \\
\hline & & IPA & $\begin{array}{l}\text { Tulisan hasil analisis gambart } \\
\text { aktifitas perubahan bentuk } \\
\text { energi }\end{array}$ & 72,91 \\
\hline & & $\begin{array}{l}\text { Bahasa } \\
\text { Indonesia| }\end{array}$ & $\begin{array}{l}\text { Menulis teks petunjuk cara } \\
\text { penggunaan listrik yang } \\
\text { aman }\end{array}$ & 74,65 \\
\hline \multirow[t]{2}{*}{2} & \multirow[t]{2}{*}{ Pertemuan 2} & PPKN & $\begin{array}{l}\text { Pelaksanaan hak dan } \\
\text { kewajiban }\end{array}$ & 76,47 \\
\hline & & SBdP & Menyanyi & 77,52 \\
\hline \multirow[t]{3}{*}{3} & \multirow[t]{3}{*}{ Pertemuan 3} & IPA & $\begin{array}{l}\text { Tulisan hasil analisis gambar } \\
\text { aktifitas perubahan bentuk } \\
\text { energi }\end{array}$ & 78,13 \\
\hline & & Indonesia & $\begin{array}{l}\text { Menulis teks petunjuk cara } \\
\text { penggunaan listrik yang } \\
\text { aman }\end{array}$ & 79,73 \\
\hline & & PJOK & $\begin{array}{l}\text { Pelaksanaan gerak dasar } \\
\text { lokomotor dan non } \\
\text { lokomotor }\end{array}$ & 79,95 \\
\hline
\end{tabular}

Berdasarkan tabel 4.2, penilaian ranah keterampilan siswa selama proses pembelajaran Subtema 2 Sumber Energi menggunakan media Gobak sodor modifikasi pertemuan 1 menunjukan nilai rata- rata keperdulian terhadap sumber daya alam 70,57, tulisan hasil analisis gambar aktifitas perubahan bentuk energi 72,91 dan menulis teks petunjuk cara penggunaan listrik yang aman 74,65. Pertemuan 2 menunjukan nilai rata-rata pelaksanaan hak dan kewajiban 76,47 dan menyanyi 77,52. Pertemuan 3 menunjukan nilai rata-rata tulisan hasil analisis gambar aktifitas perubahan bentuk energi 78,13 , menulis teks petunjuk cara penggunaan listrik yang aman 79,73 dan pelaksanaan gerak dasar lokomotor dan non lokomotor 79,95 .

Uji normalitas digunakan untuk mengetahui apakah hasil pretest peserta didik pada suatu kelas berdistribusi normal atau berdistribusi tidak normal. Data distribusi nilai pretest siswa kelas IV SD Negeri 01 Boyoteluk Kabupaten Pekalongan.

Tabel 4.3 Normalitas Awal (Pretest)

\begin{tabular}{|c|c|c|c|c|}
\hline$N$ & $a$ & $\mathrm{~L}_{0}$ & $\mathrm{~L}_{\text {thel }}$ & Kesimpulan \\
\hline 23 & 0,05 & 0,156 & 0,179 & $\begin{array}{c}\text { Berdistribusi } \\
\text { normal }\end{array}$ \\
\hline
\end{tabular}

Berdasarkan Tabel 4.3 diperoleh, $\mathrm{L}_{\mathrm{O}}=0,235$

, $\mathrm{N}=23$ dengan taraf signifikan 5\%, didapat 
877 Pengaruh Permainan Gobak Sodor Modifikasi terhadap Hasil Belajar Siswa di Sekolah Dasar- Sigit pambudi, Ibnu Fatkhu R, Diana Endah Handayani

Ltabel=0,179. Bandingkan $L_{0}$ dengan nilai kritis L(Ltabel) untuk uji lilliefors, karena $\mathrm{L}_{\mathrm{o}}<$ Ltabel atau $(0,156<0,179)$ maka Ho diterima. Jadi, data nilai pretest hasil belajar berasal dari populasi berdistribusi normal.

Uji normalitas digunakan untuk mengetahui apakah hasil posttest siswa pada suatu kelas berdistribusi normal atau tidak. Perhitungan yang digunakan untuk normalitas sampel dari populasi dilakukan dengan menggunakan uji lilliefors, pada taraf signifikan 5\%. Kriteria dalam uji normalitas adalah jika $\mathrm{L}_{\mathrm{O}}<$ Ltabel maka populasi berdistribusi normal, sedangkan jika Lo > Ltabel maka populasi berdistribusi tidak normal. Data distribusi nilai posttest siswa kelas IV SD Negeri 01 Boyoteluk Kabupaten Pekalongan dapat dilihat pada tabel berikut.

Tabel 4 Normalitas akhir (Posttest)

\begin{tabular}{|c|c|c|c|c|}
\hline $\mathrm{N}$ & $\alpha$ & $\mathrm{L}_{0}$ & $\mathrm{~L}_{\text {tabel }}$ & Kesimpulan \\
\hline 23 & 0,05 & 0,175 & 0.183 & Berdistribusinomal \\
\hline
\end{tabular}

Berdasarkan Tabel 4.4 diperoleh, $\mathrm{Lo}_{\mathrm{O}}=0,175$, $\mathrm{N}=23$ dengan taraf signifikan 5\%, didapat Ltabel= 0.183 Bandingkan Lo dengan nilai kritis L(Ltabel) untuk uji lilliefors, karena $\mathrm{L}_{\mathrm{O}}<$ Ltabel $(0,175$ $<0,179)$ maka Hoditerima. Jadi, data nilai posttest hasil belajar berasal dari populasi berdistribusi normal.

Uji hipotesis pada penelitian ini, peneliti menggunakan uji t-test yang dilakukan untuk membandingkan hasil data dari perhitungan pretest dan pottest serta menentukan ada atau tidaknya perbedaan sebagai akibat dari perlakuan $\mathrm{X}$ yaitu pembelajaran mengunakan media gobak sodor modifikasi terhadap hasil belajar dianalisis dengan uji t-test. Hipotesis yang diajukan dalam penelitian ini adalah terdapat pengaruh media gobak sodor modifikasi terhadap hasil belajar siswa kelas IV tema 2 selalu berhemat energi SD Nengri 01 Boyoteluk Kabupaten Pekalongan.
$\mathrm{H}_{\mathrm{o}}$ : Tidak ada Pengaruh hasil belajar siswa menggunakan Media gobak sodor modifikasi Kelas IV Tema 2 Selalu Berhemat Energi SD Negri 01 Boyoteluk Kabupaten Pekalongan.

$\mathrm{H}_{\mathrm{a}}$ : Terdapat pengaruh hasil belajar siswa mengunakan Media Gobak Sodor Modifikasi kelas IV Tema 2 Selalu Berhemat Energi SD Negri 01 Boyoteluk Kabupaten Pekalongan.

Setelah dilakukan analisis maka disajikan pada tabel sebagai berikut:

\section{Tabel 5 Hasil Perhitungan Uji-t Hasil Belajar} Siswa

\begin{tabular}{|c|c|c|c|c|c|c|c|}
\hline Subvek & $\begin{array}{r}\text { Hasil } \\
\text { Belajar }\end{array}$ & $\begin{array}{c}\text { Rata- } \\
\text { rata }\end{array}$ & $\mathrm{N}$ & $\mathrm{M}_{\mathrm{d}}$ & $\sum \mathrm{x}^{2} \mathrm{~d}$ & thitum & tabel \\
\hline $\begin{array}{l}\text { Kelas IV } \\
\text { SD N 01 } \\
\text { Boyoteluk }\end{array}$ & Pretest & 62,8 & 23 & 14,5652 & 2345,652 & 67,65 & 1,7171 \\
\cline { 2 - 7 } & Posttest & 76,9 & 23 & 14,5652 & 2345,652 & 67,65 & 1,7171 \\
\hline
\end{tabular}

Berdasarkan Tabel 4.5 analisis data hasil belajar Pretest dan posttest dengan uji-t bahwa diperoleh dengan nilai rata-rata pretest 62,8 dan rata-rata nilai posttest sebesar 76,9. Dengan $\mathrm{N}=$ $23, \mathrm{db}=23$ Diperoleh $\mathrm{t}_{\text {hitung }}=67,65$ dengan $\mathrm{N}=\mathrm{db}$ $\mathrm{N}-1=23-1=22$ dengan taraf signifikan 5\% sebesar 0,226. Karena $t_{\text {hitung }}=67,65>t_{\text {tabel }}=0,226$. Maka hal ini menunjukkan bahwa uji $\mathrm{t}$ hasil belajar signifikan. Hal ini menunjukkan bahwa terdapat pengaruh pembelajaran media gobak sodor modifikasi terhadap hasil belajar siswa kelas IV tema 2 selalu berhemat energi SD Negri boyoteluk 01 Kabupaten Pekalongan.

Apabila siswa telah mencapai nilai KKM 75 terhadap subtema sumber energi. Berikut tabel ketuntasan belajar individu. 
878 Pengaruh Permainan Gobak Sodor Modifikasi terhadap Hasil Belajar Siswa di Sekolah Dasar- Sigit pambudi, Ibnu Fatkhu R, Diana Endah Handayani

Tabel 6 Tabel Ketuntasan Belajar Individu

\begin{tabular}{|l|l|l|l|}
\hline No. & Kriteria & Pretest & Posttest \\
\hline 1. & Nilai tertinggi & 85 & 95 \\
\hline 2. & Nilai terendah & 40 & 50 \\
\hline 3. & Rata-rata & 62,8 & 76,1 \\
\hline 4. & Siswa tuntas & 5 & 20 \\
\hline 5. & Siswa tidak tuntas & 18 & 3 \\
\hline
\end{tabular}

Berdasarkan Tabel 4.6 dapat disimpulkan bahwa hasil nilai posttest lebih baik dari pada hasil nilai pretest, hal ini dibuktikan dengan hasil akhir yang diperoleh siswa pada nilai pretest ada 17 siswa yang tidak mencapai KKM dan 6 siswa yang mencapai KKM, dengan rata-rata nilai kelas 62,8 . Sedangkan hasil nilai posttest lebih baik karena yang tidak mencapai KKM ada 3 siswa dan 20 siswa yang mencapai KKM, dengan rata-rata nilai kelas 76,9. Berikut disajikan diagram batang untuk memperjelas data ketuntasan belajar individu:

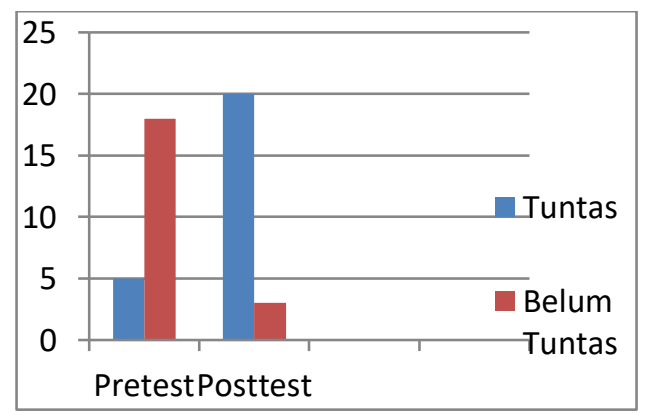

\section{Gambar 1 Diagram Ketuntasan Belajar Individu}

Perhitungan untuk mengetahui berapa besar persentase ketuntasan siswa dalam kelas tersebut. Berikut disajikan tabel ketuntasan belajar klasikal.

Tabel 7 Ketuntasan Belajar Klasikal

\begin{tabular}{|l|l|l|l|}
\hline \multicolumn{4}{|c|}{ Ketuntasan Belajar Klasikal } \\
\hline $\begin{array}{l}\text { Jumlah } \\
\text { siswa }\end{array}$ & Tuntas & Persentase & Kategori \\
\hline 23 & 20 & 87 & Tuntas \\
\hline
\end{tabular}

Depdiknas (2006) menjelaskan bahwa kelas dikatakan tuntas secara klasikal apabila kelas tersebut mencapai kriteria ketuntasan belajar klasikal sebesar 85\%. Berdasarkan Tabel 4.7, jumlah siswa yang tuntas yaitu 20 siswa. Dengan begitu, dapat dikatakan bahwa ketuntasan belajar klasikal kelas tersebut dengan hasil persentase $87 \%$ dapat dinyatakan tuntas secara klasikal.

Pembahasan ini berisi tentang hasil penelitian yang dilaksanakan oleh peneliti pada siswa kelas IV SD Negri 01 Boyoteluk Kabupaten Pekalongan. Rancangan dan desain penelitian One Group Pretest- Posttest Design. Pelaksanaan penelitian ini diberikan lembar soal Pretest di awal pembelajaran untuk mengetahui hasil belajar Tematik siswa sebelum diberikan perlakuan. Peneliti memberikan perlakuan (treatment) dengan menggunakan media gobak sodor modifikasi sebanyak 3 kali pembelajaran untuk meningkatkan hasil belajar Tema 2 Selalu Berhemat Energi. Dalam setiap pembelajaran, dan lembar evaluasi untuk mengetahui tingkat pemahaman materi siswa saat diberi perlakuan pada setiap pembelajaran. Setelah diberikan perlakuan dengan menggunakan media gobak sodor modifikasi sebanyak 3 kali pembelajaran, peneliti memberikan lembar soal posttest untuk mengetahui peningkatan hasil belajar.

Selain nilai pretest dan posttest yang akan digunakan sebagai nilai aspek kognitif, terdapat pula penilaian ketrampilan melalui lembar observasi sebagai penilaian psikomotorik, pelaksanaan media gobak sodor modifikasi berjalan dengan baik, Ketika kegiatan peertemuan ke-1 sampai dengan kegiatan pertemuan ke-3 berlangsung, rata rata keterampilan siswa selama proses pembelajaran Subtema 2 Sumber Energi menggunakan media gobak sodor modifikasi menunjukkan rata-rata nilai keterampilan pertemuan awal keperdulian dengan sumberdaya alam 70,57, tulisan hasil analisis gambar aktifitas 
perubahan bentuk energi 72,91 dan menulis teks petunjuk cara mengunakan listrik yang aman 74,65 pada akhir pertemuan tulisan hasil analisis gambar perubahan bentuk energi 78,13 , menulis teks petunjuk cara mengunakan listrik yang aman 79,73 dan pelaksanaan gerak dasar lokomotor dan non lokomotor 79,95 dengan ini dapat disimpulkan bahwa siswa kelas IV SD Negri 01 Boyoteluk Kabupaten. Dalam ranah ketrampilan mengalami Peningkatan.

Menurut Fudyartanto dalam Baharuddin dan Wahyuni (2015: 15) Dalam kamus besar bahsa indonesia, secara etismologis belajar memiliki arti "berusaha memperoleh kepandaian atau ilmu". Definisi ini memiliki pengertian bahwa belajar adalah kegiatan untuk mencapai kepandaian atau ilmu. Di sini, usaha untuk mencapai kepandaian atau ilmu merupakan usaha manusia untuk memenuhi kebutuhannya mendapat ilmu atau kepandaian yang belum dipunyai sebelumnya. Sehingga dengan belajar itu manusia menjadi tahu, memahami, mengerti, dapat melaksanakan dan memiliki tentang sesuatu.

Berdasarkan teori yang dipaparkan diatas, sesuai dengan hasil penelitian mengenai pengaruh media gobak sodor modifikasi terhadap hasil belajar siswa kelas IV Tema 2 Selalu Berhemat Energi SD Negri 01 Boyoteluk Kabupaten Pekalongan. Membuat siswa tertarik dan memperhatikan apa yang disampaikan penelitian sehingga belajar siswa mengalami peningkatan hal ini sejalan dengan teori Bell-Gredler dalam Baharuddin dan Wahyuni (2015: 13-14) berpendapat Kemampuan manusia untuk belajar merupakan karakteristik penting yang membedakan manusia dengan makhluk hidup lainnya. Belajar mempunyai keuntungan baik bagi individu maupun bagi masyarakat. Bagi individu, kemampuan untuk belajar secara terus-menerus akan memberi kontribusi terhadap pengembagan kualitas hidupnya.
Setelah dilakukan analisis data hasil belajar pada aspek kognitif data hasil belajar Pretest dan posttest bahwa diperoleh dengan nilai rata-rata pretest 62,8 dan rata-rata nilai posttest sebesar 76,9. Dengan $\mathrm{N}=23, \mathrm{db}=23$ Diperoleh $\mathrm{t}_{\text {hitung }}=$ 67,65 dengan $\mathrm{N}=\mathrm{db} \mathrm{N}-1=23-1=22$ dengan taraf signifikan 5\% sebesar 0,226. Karena $t_{\text {hitung }}=67,65$ $>\mathrm{t}_{\text {tabel }}=0,226$. Maka hal ini menunjukkan bahwa uji t hasil belajar signifikan. Hal ini menunjukkan bahwa terdapat pengaruh pembelajaran media gobak sodor modifikasi terhadap hasil belajar siswa kelas !V tema 2 selalu berhemat energi SD Negri boyoteluk 01 Kabupaten Pekalongan. Hal ini sesuai dengan pengertian Hasil belajar adalah kemampuan-kemamampuan yang dimiliki siswa setelah ia menerima pengalaman belajarnya. (Horward Kingsley) membagi tiga macam hasil belajar, yakni ketrampilan dan kebiasaan, pengetahuan dan pengertian, sikap dan cita-cita. (Gagne) membagi lima kategori hasil belajar, yakni informasi verbal, ketrampilan intelektual, strategi kognitif, sikap dan ketrampilan motoris. (Beyamin Bloom) membagi tiga ranah yakni ranah kognitif, ranah afektif, dan ranah pesikomotoris. ( Sudjana, 2009 : 22-23) hal ini juga sesuai dengan undang-undang Republik Indonesia Nomor 20 tahun 2003 yang menyebutkan bahwa “ pendidikan adalah usaha sadar dan terencana untuk mewujudkan sesuai belajar dan proses pembelajaran agar peserta didik secara aktif mengembangkan potensi dirinya untuk memiliki spiritual keagamaan. pengendalian dirkepribadian, kecerdasan, akhlak mulia, serta ketrampilan yang diperlukan dirinya, masyarakan, bangsa dan negara".

Proses pembelajaran 1 dengan menggunakan media gobak sodor modifikasi disambut baik oleh siswa. Saat pembelajaran pertama banyak siswa yang belum mengetahui alur pembelajaran dalam bermain media gobak sodor modifikasi, tetapi siswa merasa senang dengan adanya suasana baru. 
Selain itu, siswa masih belum terampil dan kompak dalam melakukan kegiatan diskusi dalam permainan gobak sodor modifikasi. Nilai ketrampilan siswa pada pembelajaran 1 didapatkan nilai rata-rata sebesar 70,57, 72,91 dan 74,65. Dalam aspek ketrampilan, kriteria yang paling menonjol pada pertemuan ke-1 yaitu keterampilan menuliskan hasil analisis gambar aktifitas perubahan bentuk energi dan menuliskan teks petunjuk cara mengunakan listrik yang aman siswa terlihat antusias membaca teks petunjuk akan tetapi siswa masih merasa binggung saat memilih kosa kata baku dan kalimat efektik yang akan digunkan saat menjawab soal yang berada di kota dalam media gobak sodor modifikasi.

Pada pembelajaran 2, percaya diri siswa sudah mulai ada, hal ini dapat dilihat dari aktifitas siswa dalam bermain media permainan gobak sodor modifikasi. Siswa sudah terampil dalam diskusi di dalam kotak gobak sodor modifikasi dan siswa mampu menuliskan hasil diskusi dengan baik. Selain itu, siswa juga percaya diri dalam menyanyikan lagu "Menanam Jagung", sesuai dengan syair lagu, siswa juga sudah terampil dalam bermain media gobak sodor modifikasi serta mampu menjawab pertanyaan yang ada dalam kotak di media gobak sodor modifikasi terlihat tidak kebinggungan. pengamatan aktivitas siswa pada ranah keterampilan didapatkan nilai rata-rata sebesar 76, 47 dan 77,52 karena pada pembelajaran 2 siswa sudah mengetahui alur bermain media gobak sodor dalam pembelajaran.

Pada pembelajaran 3, merupakan pembelajaran terakhir dengan menggunakan perlakuan media gobak sodor modifikasi, siswa sudah bisa melakukan kegiatan diskusi di dalam bermain gobak sodor modifikasi dengan baik. Siswa sangat antusias dan bersemangat dikarenakan pada pembelajaran 3 merupakan penentuan juara pada permainan gobak sodor modifikasi. Dalam aspek ranah ketrampilan, terlihat kemampuan siswa saat menjawab pertanyaan yang terdapat dalam kotak gobak sodor modifikasi dengan tidak merasa kebinggungan serta ragu-ragu dalam memilih kata efektif dan terlihat kerapihan penulisan laporan pengamatan aktivitas siswa pada ranah keterampilan didapatkan nilai rata-rata sebesar 78,13, 79.73 dan 79,95. Peningkatan nilai aktivitas siswa tersebut sejalan dengan hasil laporan diskusi yang disusun oleh masing-masing kelompok. Pada akhir pembelajaran, peneliti menentukan perolehan juara dengan menjumlah point dari pembelajaran 1 hingga 3 pada setiap kelompok. Setelah itu peneliti memberikan lembar evaluasi hasil belajar (posstest).

Pembelajaran 1 hingga 3 selalu mengalami kenaikan aktivitas siswa. Hasil penelitian ini didukung oleh Hardiyanti dan lutfi (2013) menyatakan bahwa media permainan gobak sodor dapat digunakan untuk media pembelalajaran karena bersifat drill atau latihan soal sehingga siswa lebih banyak berlatih untuk memahamkan materi unsur dan senyawa kimia sederhana dengan cara yang lebih menyenangkan sehingga terjadi peningkatan hasil belajar dan dari tes hasil belajar siswa mengalami peningkatan yang cukup baik

\section{SIMPULAN}

Media gobak sodor modifikasi berpengaruh terhadap Berdasarkan hasil penelitian yang didasarkan pada analisis data statistik serta kenyataan di lapangan maka dapat disimpulkan bahwa media gobak sodor modifikasi berpengaruh terhadap hasil belajar peserta didik Tema 2 Selalu Berhemat Energi kelas IV SD Negeri 01 Boyoteluk Kabupaten Pekalongan. Pengaruh tersebut dapat dilihat dari hasil uji-t bahwa diperoleh $t_{\text {hitung }}>\mathrm{t}_{\text {tabel }}$ yaitu $\mathrm{t}_{\text {hitung }}=67,65>\mathrm{t}_{\text {tabel }}=$ 1,7171 jadi $\mathrm{H}_{0}$ ditolak dan $\mathrm{H}_{\mathrm{a}}$ diterima. Dengan demikian dapat disimpulkan bahwa hasil belajar peserta didik Tema 2 Selalu Berhemat Energi kelas 
881 Pengaruh Permainan Gobak Sodor Modifikasi terhadap Hasil Belajar Siswa di Sekolah Dasar- Sigit pambudi, Ibnu Fatkhu R, Diana Endah Handayani

IV SD Negeri 01 Boyoteluk Kabupaten

Pekalongan.

\section{DAFTAR PUSTAKA}

Danim, Sudarwan. 2014.Perkembangan Peserta Didik. Bandung: Alfabeta.

Lutfi \& Hardiyanti. (2013). Meningkatkan Hasil Belajar Siswa Pada Pembelajaran Unsur dan Senyawa Kimia Sederhana dengan Mengunakan Permainan Tradisional Gobak Sodor. Unesa Jurnal Of chemical Education, 2(2), 7-11.

https://jurnalmahasiswa.unesa.ac.id/index. php/journal-of-chemicaleducation/article/download/2720/1620 Diakses pada tanggal 27 juni 2019 pukul 6.20

Nur Wahyuni, Esa\&Baharuddin.2011. Teori Belajar \& Pembelajaran. Yogyakarta: ArRuzz Media.

Sanjaya, Wina. 2012. Media Komunikasi Pembelajaran. Jakarta: Prenada Media Group.

Sudjana, Nana. 2009. Penilaian Hasil Proses Belajar. Bandung: PT Remaja Rosdakarya.

Sugiyono. 2016. Metode Penelitian Pendidikan; Pendekatan Kuantitatif, Kualitatif dan $R \& D$. Bandung: Alfabeta 